\title{
Education
}

\section{Teaching the RAPID approach at the start of emergency medicine clerkship: an evaluation}

\author{
Robert A. Woods, MD, MMEd*; Krista Trinder, $\mathrm{MA}^{\dagger}$; Marcel D’Eon, $\mathrm{PhD}^{\dagger}$; Sean McAleer, DPhil ${ }^{\ddagger}$
}

\section{ABSTRACT}

Background: The RAPID approach (Resuscitation, Analgesia and assessment, Patient needs, Interventions, Disposition) was developed as an approach to managing emergency department patients. It is a mental checklist to help trainees provide comprehensive care, addressing issues in priority. Its impact on trainee performance has not been assessed.

Methods: Forty-two clerkship students were enrolled, with 21 students in each group. They received or did not receive the teaching intervention on an alternate basis. Students were assessed through daily encounter cards, a case presentation, a self-assessment form, a prerotation case (case E), and a sixcase short-answer exit examination (cases $A$ to $F$ ) with case $E$ repeated. Case $E$ was designed specifically to assess students' ability to provide comprehensive care. Fourteen students participated in focus groups.

Results: Students in the intervention group had significantly higher exit examination case E scores (11.67 of $14 \mathrm{v}$. 10.26 of $14, p=0.008)$ and improvement in their case $E$ scores from pre- to postrotation (1.82 v. $0.26, p=0.006$ ). There were no significant differences in the other outcome measures. Intervention group students made positive comments around analgesia, addressing nonmedical needs and counseling on health promotion during focus groups.

Conclusions: Students exposed to the RAPID approach at the start of their emergency medicine rotation performed better on the one component of the written examination for which it was designed to improve performance. Students found it to be a useful mental checklist for comprehensive care, possibly addressing the hidden curriculum. Emergency medicine educators should consider further study and careful implementation of the RAPID approach.

\section{RÉSUMÉ}

Contexte: La méthode RAPID (acronyme anglais: Resuscitation, Analgesia and assessment, Patient needs, Interventions, Disposition) a été conçue comme un moyen mnémotechnique de traiter les patients au service des urgences. II s'agit d'une liste de vérification mentale, qui aide les stagiaires à fournir des soins complets et à traiter les problèmes en ordre de priorité. Toutefois, son incidence sur le rendement des stagiaires n'a pas fait l'objet d'évaluation. Méthode: Quarante-deux étudiants en stage, divisés en groupes de 21 sujets chacun, ont participé à l'étude. Ils ont reçu ou non, en alternance, cette formation pédagogique. Les étudiants ont été soumis à différentes formes d'évaluation: fiches de rencontres quotidiennes, exposé de cas, formulaire d'auto-évaluation, étude de cas avant le stage (cas $\mathrm{E}$ ), et examen de fin de stage à réponse courte sur six cas (cas $A$ à $F$ ) avec reprise du cas $E$. Ce dernier avait été conçu précisément pour évaluer la capacité des étudiants à fournir des soins complets. Quatorze étudiants ont fait partie des groupes de réflexion.

Résultats: Les étudiants du groupe expérimental ont obtenu, à l'examen de fin de stage, des résultats sensiblement meilleurs que ceux de l'autre groupe en ce qui concerne le cas $E$ ( 11.67 sur 14 contre [c.] 10.26 sur $14 ; p=0.008$ ); ils ont aussi amélioré leurs propres résultats en ce qui concerne l'étude du cas $\mathrm{E}$, avant et après le stage (1.82 c. $0.26 ; p=$ 0.006). Quant aux autres critères d'évaluation, aucun écart important n'a été relevé. Les étudiants du groupe expérimental ont fait des observations favorables sur l'analgésie, la manière de répondre aux besoins non médicaux, et les conseils sur la promotion de la santé, durant les séances de réflexion.

Conclusions: Les étudiants soumis à la méthode RAPID au début de leur stage en médecine d'urgence ont mieux réussi que les autres à l'élément de l'examen écrit pour lequel la formule avait été conçue afin d'améliorer le rendement. De I'avis des étudiants, la liste mentale s'est avérée utile dans la prestation de soins complets, corrigeant peut-être ainsi le programme "caché». Les formateurs en médecine d'urgence devraient envisager une étude approfondie et une mise en œuvre minutieuse de la méthode RAPID.

Keywords: approach, clerkship, emergency medicine, health promotion, hidden curriculum, mnemonic, oligoanalgesia

From the *Department of Surgery and tEducational Support and Development Unit, University of Saskatchewan, Saskatoon, SK, and $\ddagger$ Centre for Medical Education, Dundee, Scotland.

Correspondence to: Dr. Robert A. Woods, Room 2689, 107 Hospital Drive, Royal University Hospital, Saskatoon, SK S7N 0W8; rob.woods@ usask.ca.

This article has been peer reviewed 
It has been previously recognized that clinic-based education differs from team-based hospital education in terms of educational time commitment. Compared to ward-based learning, the learner is the more committed party in clinic settings. The clinician is focused on patient care, and the time for effective teaching can be limited. ${ }^{1}$ In response to this, the SNAPPS mnemonic was developed for students to "assume a central role in structuring the learning interaction." "The SNAPPS mnemonic consists of the following: Summarize the history and findings, Narrow the differential, Analyze the differential, Probe the preceptor about uncertainties, Plan management, Select case-related issues for self-study. When studied in the family medicine clinic setting, it was found to "greatly facilitate and enhance expression of diagnostic reasoning and uncertainties during case presentations to ambulatory care preceptors.",

The emergency department (ED) is similar to the clinic-based environment in that teaching time is limited and the learner has the larger educational time commitment. ${ }^{4-6}$ In addition to this, patients in the ED do not present at fixed intervals, occasionally require resuscitation, are often in pain, have a high incidence of nonmedical needs in addition to medical needs, and require more effective discharge instructions or arrangement of follow-up care because this is often the only encounter that the physician will have with that patient. There is evidence that practicing physicians and nurses fail to consistently manage these challenges. ${ }^{7-11}$ Trainees are put into an environment that is unfamiliar and unpredictable, where their teachers have very little time to teach and do not always role model effectively.

Davenport and colleagues developed the 3-minute clinical presentation specifically for students in the ED. ${ }^{12}$ The strength of this guide is how it gets students to focus on the appropriate relevance and chronology of items in the history of presenting illness. It encourages the learner to complete the oral presentation in less than 3 minutes. It encourages learners to think of the worst possible diagnosis, bringing out the concepts of resuscitation and clinical reasoning. It also lists identifying the plan for the patient, encouraging students to take ownership of patient care. Its focus, however, is on the oral presentation, not the overall patient approach. As an intervention, it is targeted more at the faculty than at the student.

The RAPID approach, described in (Table 1), is "an overall approach to patient management in the Emergency Department." ${ }_{13}$ This approach has many theoretical advantages. It puts the traditionally taught history and physical examination into the appropriate context of the ED encounter and emphasizes important but often neglected areas of patient management. It has been designed to function like a mental checklist, where you cannot move on until you are satisfied that each checklist item is met. It has high face validity as a guide for students in the ED; however, it has not been studied to see if it impacts student performance. We set out to see if students exposed to the RAPID approach performed better when evaluated on a comprehensive care scenario relevant to the ED setting.

\begin{tabular}{|c|c|}
\hline RAPID & Prompting questions \\
\hline Resuscitation & $\begin{array}{l}\text { Does my patient require any resuscitative interventions? } \\
\text { Do the vital signs and/or chief complaint raise concerns, which need close monitoring? } \\
\text { Does the chief complaint mandate urgent investigations for possible time-sensitive illness (i.e., stroke, heart } \\
\text { attack, sepsis)? }\end{array}$ \\
\hline Analgesia and assessment & $\begin{array}{l}\text { Is my patient in any pain or discomfort? Should I address it now or after my full assessment? } \\
\text { History and physical examination } \\
\text { What is my differential diagnosis? }\end{array}$ \\
\hline Patient needs & $\begin{array}{l}\text { What are my patient's nonmedical needs? } \\
\text { How will the patient's social situation, values, and preferences impact my management plan? }\end{array}$ \\
\hline Interventions & $\begin{array}{l}\text { What tests will I order? What treatments will I provide? } \\
\text { What is the end point of my workup? What will I do if all of my tests are normal? }\end{array}$ \\
\hline Disposition & $\begin{array}{l}\text { If I am sending my patient home, does he or she understand the diagnosis or suspected diagnosis? } \\
\text { Prescriptions? When to return if things change? } \\
\text { Do I need to arrange any follow-up tests/consultations? What is the contingency plan if the patient does not } \\
\text { hear about these follow-up arrangements? } \\
\text { Can I address any preventive health issues? }\end{array}$ \\
\hline
\end{tabular}




\section{METHODS}

This study was approved by the Behavioural Research Ethics Board at the University of Saskatchewan. Clerkship students completing a core or elective rotation in emergency medicine (EM) in Saskatoon, Saskatchewan, were eligible for the study. The study period was January to December of 2010. Forty-two students completed a 2-week EM rotation during the study period, all of whom agreed to be involved in the study. Consent was requested and obtained by a research assistant, and students were assured that their participation would have no impact on their assessment for the rotation. This was made explicit as the author was the clerkship director at the time. A different emergency physician compiled the summative evaluations for the rotation for the duration of the study to avoid any conflicts of interest.

All students, regardless of the study arm, worked one on one with an attending emergency physician for each shift. Supervising emergency physicians completed a daily encounter card (DEC) for each shift. They were not aware of the study groups and were not given any information on the nature of the study; however, if the faculty noticed a student with a pocket card, they may have been aware that the student was in the intervention group. Students were instructed not to inform their preceptors about which arm of the study they were in.

As part of the rotation and not part of the study but simply as concurrent training, students in both groups received a 2-hour teaching session on procedural skills: suturing, casting, nasal packing, and slit-lamp examination. They also received a 4-hour introductory teaching session on resuscitation using a high-fidelity simulator, with the following core simulation cases: airway obstruction (anaphylaxis), respiratory distress (congestive heart failure), shock (upper gastrointestinal bleeding), and altered mental status (intoxication/ trauma).

Sixteen groups of students were enrolled. The sizes of the groups ranged from one student to six students per block. Groups of students were provided with the intervention or not on an alternate basis, with the first group of students to rotate through being an intervention group. This method was chosen to minimize experience bias and contamination bias.

Twenty-one students in eight groups were given the intervention. These students each received a pocket card and a short handout on the RAPID approach during their 1-hour teaching intervention. The pocket card had a list of normal vital signs, doses of commonly used analgesics and antinauseants, and the RAPID descriptors and associated prompting questions (see Table 1). One author (R.A.W.) provided this intervention on the first day of the rotation. After a brief explanation of the RAPID approach and familiarization with the pocket card, students worked through five theoretical ED cases in small-group format. It was up to them to use the RAPID approach and materials from that point forward. Twenty-one students in eight groups were the control group; they did not receive the pocket card, handout, or small-group session.

\section{Quantitative outcomes}

Students were assessed through DECs, a case presentation, a self-assessment form, a prerotation case (case E), and a six-case short-answer exit examination (cases A to F) with the prerotation case (case E) repeated. The DEC was in the format of a rubric where 16 categories of performance had descriptors of what constituted below, meets, and exceeds expectations. The case presentation occurred during the second week of the rotation at our EM academic half-day. Students were instructed to choose one patient from their rotation who presented with an undifferentiated complaint. They were given a template on how to present it. The faculty member or EM resident responsible for supervising the academic halfday completed the case presentation evaluation form. The evaluation form was based on elements of the RAPID approach.

Case $\mathrm{E}$ on the examination asked questions to explicitly address comprehensive care for the patient: resuscitation, provision of analgesia, differential diagnosis, interpretation of test results, provision of discharge advice, and ensuring the safety and reliability of patient follow-up. This case was designed by the author as an assessment of comprehensive care. The remainder of the cases focused on differential diagnosis and initial investigations for undifferentiated complaints. The exit examination consisted of the following cases: case A (chest pain), case B (shortness of breath), case $\mathrm{C}$ (headache), case $\mathrm{D}$ (poisoned patient), case $\mathrm{E}$ (bleeding in early pregnancy), and case $\mathrm{F}$ (acute coronary syndrome). A trained, independent assessor marked the exit examination and prerotation case using a standardized answer key. The examination was out of 
94 possible points. The examination, apart from case $\mathrm{E}$, had been in place for 6 months prior to the launch of the study and was developed by the EM education coordinators in both Saskatoon and Regina.

\section{Statistics}

Independent samples $t$-tests and chi-square tests were conducted to determine whether there were any differences between the two groups. Effect sizes (Cohen $d$ ) were calculated as practical measures of significance, where 0.2 is considered small, 0.5 medium, and 0.8 large. Forty-two students were required to determine a large effect size on case $\mathrm{E}$ of the exit examination.

\section{Focus groups}

At the completion of the study period, eight students from the intervention group (two groups of three students and one group of two students) and six students from the control group (two groups of three students) volunteered to participate in postrotation focus groups to gather qualitative information about their experiences with approaching patients in the ED. A trained facilitator, with a standardized set of questions, led the focus groups. The facilitator did not have a formal relationship with the participants and was not responsible for assessment at any point in the undergraduate curriculum.

Focus group questions for both groups were based on all aspects of the RAPID approach, worded in terms of caring for ED patients. Participants in the intervention group were asked about the effectiveness of the RAPID mnemonic, the method of instruction, and specific areas that RAPID was designed to address. Participants in the control group were asked about their experiences in these same areas. Consent was obtained for recording the discussion. The facilitator analyzed data, consisting of audio recordings and focus group notes. Because the focus group questions were structured, question analysis was used in which responses were sorted by question. ${ }^{14}$

\section{RESULTS}

\section{Quantitative outcomes}

The groups were compared for baseline demographic data (Table 2). There were statistically significant

\begin{tabular}{|c|c|c|c|}
\hline Demographic & $\begin{array}{l}\text { Intervention } \\
(n=21)\end{array}$ & $\begin{array}{l}\text { Control } \\
(n=21)\end{array}$ & $p$ value \\
\hline Age, mean (SD) & $26.81(4.46)$ & 25.67 (3.35) & .353 \\
\hline \multicolumn{4}{|l|}{ Gender } \\
\hline Male & 10 & 12 & .537 \\
\hline Female & 11 & 9 & \\
\hline \multicolumn{4}{|l|}{ EM as career } \\
\hline Yes & 5 & 11 & .032 \\
\hline No & 11 & 3 & \\
\hline Maybe & 5 & 6 & \\
\hline \multicolumn{4}{|l|}{$\begin{array}{l}\text { Health care } \\
\text { professional }\end{array}$} \\
\hline Yes & 6 & 1 & .038 \\
\hline No & 15 & 20 & \\
\hline \multicolumn{4}{|l|}{$\begin{array}{l}\text { Previous } \\
\text { shadowing in EM }\end{array}$} \\
\hline Yes & 11 & 16 & .107 \\
\hline No & 10 & 5 & \\
\hline \multicolumn{4}{|l|}{$\begin{array}{l}\text { EM rotation: core } \\
\text { v. elective }\end{array}$} \\
\hline Core & 20 & 13 & .008 \\
\hline Elective & 1 & 8 & \\
\hline
\end{tabular}

differences in three areas. There were more individuals in the intervention group who had previous experience as health care professionals. The students in the control group were more likely to be considering EM as a career option and were more likely to be completing an elective rotation versus a core rotation. The two groups were similar in their prerotation case E scores, self-assessment scores, oral case presentation scores, and DECs (Table 3).

The intervention group scored significantly better in the postrotation case $\mathrm{E}(11.7$ v. 10.3 of $16 ; t(40)=$ 2.82, $p=0.008, d=0.87)$, and their score improved more than that of the control group $(+1.9 \mathrm{v} .+0.26$; $t(40)=2.92, p=0.006, d=0.90)$. Although overall exit examination scores were also higher, this difference did not meet statistical significance.

\section{Focus groups}

Students in the intervention group found that the RAPID approach and the method by which it was taught to be effective (Table 4). Those exposed to the approach found that it reminded them to provide comprehensive care and not forget about pain management and social issues. Students in the intervention 
Table 3. Performance outcomes: written examination, self-assessment, case presentation, and daily encounter cards

\begin{tabular}{|c|c|c|c|}
\hline Measure & $\begin{array}{c}\text { Intervention }(n=21) \\
\text { Mean }(S D)\end{array}$ & $\begin{array}{l}\text { Control }(n=21) \\
\text { Mean (SD) }\end{array}$ & $\begin{array}{c}\text { Statistical } \\
\text { significance }(p)\end{array}$ \\
\hline Prerotation case E score $(x / 16)$ & $9.76(1.77)$ & $10.00(2.02)$ & .687 \\
\hline Postrotation case $E$ score $(x / 16)$ & $11.67(1.53)$ & $10.26(1.70)$ & .008 \\
\hline Change in E score & $1.90(2.12)$ & $0.26(1.46)$ & .006 \\
\hline Exit examination overall score $(x / 94)$ & $74.67(4.97)$ & $70.43(8.83)$ & .062 \\
\hline Self-assessment prerotation (10 point Likert scale) & $6.21(1.32)$ & $5.79(1.25)$ & .296 \\
\hline Self-assessment postrotation (10 point Likert scale) & $8.05(0.77)$ & $7.74(0.75)$ & .195 \\
\hline Case presentation $(x / 50)$ & $39.9(3.58)$ & $38.9(4.72)$ & .444 \\
\hline Daily encounter card* & $0.115(0.09)$ & $0.119(0.10)$ & .913 \\
\hline
\end{tabular}

group had positive comments in the area of initial assessment, provision of analgesia, addressing nonmedical needs, disposition planning, and health counseling (Table 5).

\section{DISCUSSION}

A brief introduction to the RAPID approach resulted in a statistically significant increase in the examination score of case E. The bulk of the questions on the casebased examination revolved around generating a differential diagnosis, ordering the initial treatments, and ordering the appropriate investigations for an undifferentiated patient. The RAPID approach did not attempt to augment medical knowledge but instead to prioritize the approach to the patient and to highlight important but neglected areas of care. Some examples of these areas of care are provision of analgesia, addressing nonmedical needs, and having comprehensive discharge instructions for patients.

Only case $\mathrm{E}$ on the examination had these issues explicitly embedded in the questions, and there was a significant difference in the scores for this case.
Students were required to address resuscitation, pain management, and differential diagnosis; to interpret the results of investigations; to give discharge advice; and to ensure reliable follow-up as well as safety by screening for domestic violence. The remainder of the cases did not lend themselves to addressing social or discharge issues. RAPID made a difference in student learning in the areas for which it was designed.

The DECs did not detect a difference between the groups. The phenomenon of leniency bias may have minimized any actual difference between the groups. ${ }^{15}$ These researchers discovered that out of 801 daily encounter cards collected from 43 physicians, only $1.3 \%$ identified a competency as "needs attention." In our study, not a single "below expectations" was identified out of the 163 DECs collected. Barriers to providing effective feedback and evaluation are time pressure, discomfort with stating something negative, fear of being judgmental, lack of confidence in teaching effectively, and past experience with embarrassing or humiliating feedback. ${ }^{16}$ The reasons for the lack of negative feedback were not elicited specifically from the faculty in our study. Informally, faculty

Table 4. Satisfaction with the RAPID approach

Discussion topic

Were there any aspects of care you would have neglected without the mnemonic?

What aspects of the teaching intervention were effective/ineffective?

\footnotetext{
"Patient needs, such as asking if there is anyone who needs to be notified that the patient is in emergency"

"Patient discomfort is a priority"

"Early emphasis on social aspects"

"In new situations you might skip over things; RAPID helps with this"

"Addressing pain management early"

"Looking at the complete picture, patient outcomes. Formally consider patient needs"

"Case-based session"

"Small-group format useful for building on each other's answers"

"Pocket card useful-referred to it 2-3 times per shift"

"Normal vital signs on the first page of the pocket card, a good reminder to always check them"
} 


\begin{tabular}{|c|c|c|}
\hline Discussion topic & Intervention group & Control group \\
\hline $\begin{array}{l}\text { Recognizing abnormal vital } \\
\text { signs and signs of distress }\end{array}$ & $\begin{array}{l}\text { "This is the first thing on the list; you can } \\
\text { forget what normal is when going over so } \\
\text { many things; it is good to have it there" }\end{array}$ & $\begin{array}{l}\text { "Subtle presentations can be difficult to pick up" } \\
\text { "That's my attending's job" }\end{array}$ \\
\hline Provision of analgesia & $\begin{array}{l}\text { "RAPID is good for this; you don't always } \\
\text { know when a patient is in pain" } \\
\text { "RAPID makes you deal with discomfort } \\
\text { early on" } \\
\text { "It puts pain at the forefront" }\end{array}$ & $\begin{array}{l}\text { "Discomfort put lower on the list. Want a diagnosis first } \\
\text { before treating pain" } \\
\text { "Wasn't always sure how much medication to give" }\end{array}$ \\
\hline Nonmedical needs & $\begin{array}{l}\text { "RAPID helps you to remember to notify } \\
\text { someone that the patient is in emergency" } \\
\text { "You usually look for an acute problem, but } \\
\text { sometimes people are there for other reasons" }\end{array}$ & $\begin{array}{l}\text { "Privacy issues make this challenging" } \\
\text { "Some were willing to mention it" } \\
\text { "Nurses would often do this" }\end{array}$ \\
\hline $\begin{array}{l}\text { Injury prevention and health } \\
\text { promotion }\end{array}$ & $\begin{array}{l}\text { "I might not have thought of some things } \\
\text { otherwise" }\end{array}$ & $\begin{array}{l}\text { "Not forefront on my mind; we are dealing with treating } \\
\text { patients" } \\
\text { "We see odd injuries; it is difficult to tell them to wear a } \\
\text { "helmet" }\end{array}$ \\
\hline Disposition planning & $\begin{array}{l}\text { "You need to start making plans early } \\
\text { depending on what the results are" }\end{array}$ & $\begin{array}{l}\text { "This is experience based" } \\
\text { "Prepared in some ways, but still learning" }\end{array}$ \\
\hline
\end{tabular}

members at our institution have stated that having only one shift with a trainee makes it difficult to do a proper assessment. Students in both groups had an average of five preceptors during their rotation, so they would have many instances when a trainee had only one shift with a preceptor.

No differences were identified in the case presentation. Once again, multiple faculty members did the evaluations and were not truly blinded. Leniency bias is likely to be present with this form of evaluation as well. Also, students were given a template on how to present their case, which may have minimized any observable differences from the intervention.

Both groups felt unprepared for the clerkship rotation and offered similar responses to their perceived deficiencies and to the experiences that would have been helpful prior to the rotation. Most of their concerns were around managing critically ill patients, doing procedures, and having symptom-based approaches to problems. Students felt that the RAPID approach was helpful in teaching trainees to make assessment of vital signs and the chief complaint the first priority in the assessment of their patient. Recognition is the first aspect of developing resuscitation skills. These skills are refined with experience.

Students in the intervention group demonstrated positive comments toward providing analgesia and addressing nonmedical needs (see Table 5). It is possible that this represents part of the hidden curriculum of EM. ${ }^{17}$ Clerkship is the place where a significant decline in empathy occurs. ${ }^{18}$ Oligoanalgesia and failing to address patients' nonmedical needs are frequently cited in the EM literature. ${ }^{7,8}$ Health care providers may have accepted this current standard of practice as the norm and may be conveying this attitude to their trainees and colleagues. It is possible that RAPID could help address these aspects of the hidden curriculum.

Given the contrast in the comments between the two groups in these areas, it is surprising that there were no quantitative differences of performance on the DECs. In addition to the previously mentioned leniency bias, the hidden curriculum may have been another source of bias minimizing the effect of the intervention. Supervisors may not have noticed or not valued these areas as much as clinical reasoning. Performance ratings on their DECs in these areas may have been inappropriately lower than deserved.

Students in the intervention group felt that the small-group format was effective for teaching this mnemonic. They felt that having it in this format made them more accountable for their answers and helped them think through real cases and why they were ordering tests.

\section{LIMITATIONS}

The method of allocating students to the two groups was not true randomization ${ }^{19}$ and did lead to three differences in the groups. ${ }^{20}$ Those in the intervention group were more likely to have been a health care professional 
prior to medical school, whereas those in the control group were more likely to be pursuing EM as a career and doing an elective rather than a core rotation.

The impact of these differences noted in the two groups could bias the results in either direction. Students who are already health care professionals may have greater knowledge and experience with working in the hospital setting and may perform better, although both groups commented on how unprepared they felt for the rotation, and there was no statistically significant difference in their self-perception of competence prerotation. On the contrary, their previous experience may hinder their ability to synthesize new ways of thinking compared to the clean slate of someone who is entering medicine without a previous career. The variety of health care professionals in the study certainly adds complexity to the discussion. A nurse would likely have a much greater advantage during an ED clerkship than a naturopath or rehabilitation assistant. Overall, it is difficult to determine what impact this difference had on the data.

Students choosing to do an elective in EM and considering it as a career would likely have both a greater aptitude and interest for the specialty. EM residency training positions are highly sought after, and acquiring letters of reference is an important part of a strong application. The majority of the students choosing to do an elective in our study indicated that they were interested in EM as a career. It would be expected that the elective students were bringing their top performance to the rotation. Having a large number of elective students in the control group may have reduced the effect of the intervention.

The number of participants in our focus groups was relatively small, despite repeated calls for participation. Ideally, there should be 6 to 10 participants to gain a variety of perspectives. ${ }^{21}$ The size of our group may have limited the responses and discussion possible. Furthermore, although more general questions were asked first, some questions were very specific and may have been leading.

Students in the control group did not receive any intervention. Provision of self-directed learning materials along with independent study and peer tutoring may have reduced the effect of our intervention.

\section{FUTURE DIRECTIONS}

Given the concerns around the hidden curriculum and leniency bias, future studies of the impact of patient approaches would ideally include direct observation by trained blinded assessors in the actual clinical environment. This could serve to objectively identify performance levels and collect important quantitative data such as time to analgesia, length of stay, patients seen per hour, and duration and effectiveness of patient presentations. Additionally, surveying and interviewing patients to obtain their satisfaction of the encounter would add an important element. Alternatively, given the variability in the nature of patients students are exposed to during an ED shift, standardized patients could be used and patient presentations could be videotaped. Given that RAPID was not compared to any other similar and credible approach, a direct comparison with other approaches, such as SNAPPS or the 3-minute clinical presentation, may also be useful. Given that the SNAPPS mnemonic was studied by giving the intervention to both students and preceptors, this could be considered in future studies as well. Only having 42 students at a single centre limits the generalizability of the results. A multisite study with more participants could accomplish this.

\section{CONCLUSIONS}

Students exposed to the RAPID approach at the start of their EM rotation performed better on the one component of the written examination for which it was designed to improve performance. Students found it to be a useful mental checklist for comprehensive care, addressing the hidden curriculum. EM educators should consider further study and careful implementation of the RAPID approach.

Acknowledgements: Dr. Nadim Lalani graded short-answer examinations and completed summative in-training assessments for the students during the study period. Dr. Paul Parks, Dr. Mark Wahba and Dr. Carlo Di Gregorio helped with the RAPID mnemonic concept and initial development. Study participants were from the University of Saskatchewan College of Medicine Class of 2011.

Competing interests: None declared.

\section{REFERENCES}

1. Yonke AM, Foley RP. Overview of recent literature on undergraduate ambulatory education and a framework for future planning. Acad Med 1991;66:750-5, doi:10.1097/ 00001888-199112000-00010.

2. Wolpaw TM, Wolpaw DR, Papp KK. SNAPPS: a learnercentered model for outpatient education. Acad Med 2003;78: 893-8, doi:10.1097/00001888-200309000-00010. 
3. Wolpaw T, Papp KK, Bordage G. Using SNAPPS to facilitate the expression of clinical reasoning and uncertainties: a randomized comparison group trial. Acad Med 2009; 84:517-24, doi:10.1097/ACM.0b013e31819a8cbf.

4. Penciner R. Clinical teaching in a busy emergency department: strategies for success. CFEM 2002;4:286-8.

5. Bandiera G, Lee S, Foote J. Faculty perceptions and practice impact of a faculty development workshop on emergency medicine teaching. CFEM 2005;7:321-7.

6. Coates WC. An educator's guide to teaching emergency medicine to medical students. Acad Emerg Med 2004;11:3006, doi:10.1111/j.1553-2712.2004.tb02215.x.

7. Wilson JE, Pendleton JM. Oligoanalgesia in the emergency department. Am 7 Emerg Med 1989;7:620-3, doi:10.1016/ 0735-6757(89)90286-6.

8. Hostutler JJ, Taft SH, Snyder C. Patient needs in the emergency department: nurses' and patients' perceptions. 7 Nurs Admin 1999;29:43-50, doi:10.1097/00005110199901000-00007.

9. Hohl CM, Abu-Laban RB, Brubacher JR, et al. Adherence to emergency department prescriptions. CFEM 2009;11:131-8.

10. Friedman SM, de Dios JV, Hanneman K. Non-completion of referrals to outpatient specialty clinics among patients discharged from the emergency department: a prospective cohort study. C7EM 2010;12:325-30.

11. Engel KG, Heisler M, Smith DM, et al. Patient comprehension of emergency department care and instructions: are patients aware of when they do not understand? Ann Emerg Med 2009; 53:454-61, doi:10.1016/j.annemergmed.2008.05.016.

12. Davenport CD, Honigman BA, Druck JD. The 3-minute clinical presentation. Acad Emerg Med 2008;15:683-7, doi:10.1111/j.1553-2712.2008.00145.x.
13. Woods R, Di Gregorio C, Wahba M, et al. "RAPID" mnemonic for managing patients in the emergency department-an educational tool. CanMEDS Best Practice Abstract. Available at: http://www.royalcollege.ca/portal/page/portal/rc/common/ documents/canmeds/whatworks/canmeds_woods_mnemonic_ e.pdf (accessed November 15, 2012).

14. Morse J, Field PA. Qualitative research methods for bealth professionals. 3rd ed. Thousand Oaks (CA): Sage Publications; 1995.

15. Bandiera G, Lendrum D. Daily encounter cards facilitate competency-based feedback while leniency bias persists. CFEM 2007;10:44-50.

16. Bass BM. Reducing leniency bias in merit rankings. Personnel Psychology 2009;9:359-69, doi:10.1111/j.1744-6570. 1956.tb01074.x.

17. Hojat M, Mangione S, Nasca TJ, et al. An empirical study of decline in empathy in medical school. Med Educ 2004;38: 934-41, doi:10.1111/j.1365-2929.2004.01911.x.

18. Hojat M, Vergare MJ, Maxwell K, et al. The devil is in the third year: a longitudinal study of erosion of empathy in medical school. Acad Med 2009;84:1182-91, doi:10.1097/ ACM.0b013e3181b17e55.

19. Efird J. Blocked randomization with randomly selected block sizes. Int 7 Environ Res Public Health 2011;8:15-20, doi:10.3390/ijerph8010015.

20. Guyatt G, Sackett DL, Cook DJ. Users' guide to the medical literature: II. How to use an article about therapy or prevention: are the results of the study valid. $7 A M A 1993$; 270:2598-601, doi:10.1001/jama.1993.03510210084032.

21. Krueger RA, Casey MA. Focus groups: a practical guide for applied research. 3rd ed. Thousand Oaks (CA): Sage Publications; 2000. 